\title{
Differential Maleic Hydrazide (MH) Sensitivity Shown by the Spermatocyte Chromosomes in Five Species of Grasshoppers
}

\author{
G. K. Manna and B. B. Parida \\ Department of Zoology, University of Kalyani, \\ Kalyani, Nadia, West Bengal, India
}

Received November 13, 1970

Various workers have shown that species of animals and plants responded differentially when they were treated with ionizing radiations. Types of indices used in such studies were lethality (Demerec, Kaufmann and Hoover 1938, Spalding and Brooks 1962), growth inhibition, nuclear (Sparrow 1962) and cellular damages (Sax and Swanson 1941), X chromosome breaks (Manna and Maxumder 1968 ) etc. The importance of the determination of radiosensitivity with regard to cellular structures, specially the chromosomes is quite obvious but the reason for the differential responses has not properly been understood. On the other hand very limited attempts have been made so far to test the interspecific chemosensitivity at the chromosomal level using their aberrations as an index. Kihlman (1966) has prepared a list of chemicals which indicated a differential response with regard to their chromosome breaking activity in some species of plants and animals. These studies were conducted on the somatic chromosomes of mainly Vicia faba and Chinese hamster. Hsu and Somers (1961) obtained the chromosome breaking effect of BUdR in Chinese hamster but no such effect was found when this chemical was applied to Vicia or seedling of bean (Kihlman 1966). The differential chemosensitivity in different species of grasshoppers has already been repoted by Manna and his collaborators (Manna and Mazumder 1964, Manna and Lahiri 1966, Manna 1969). It was shown by them (Manna and Mazumder 1964) that a dose of $0.5 \mathrm{M}$ ethyl alcohol when injected into Phloeoba antennata, the $\mathrm{X}$ chromosome in the spermatocyte cells was broken. No such effect was found in Oxya velox. They further found the different frequency of chromosome aberrations in three species of grasshoppers when the adult males were injected with cupferron solution (Manna and Lahiri 1966). However, these studies were made not specifically for testing the chemosensitivity for which the present investigation was undertaken.

\section{Experimental procedure}

Adult males of five species of short-horned grasshoppers, i) Oxya velox, ii) Spathosternum prasiniferum, iii) Acrida lugula, iv) Phloeoba antennata and v) Tristria pulvinata constituted materials for the present study.

1 Prsent address: Dr. B. B. Parida, Department of Zoology, Berhampur University, Ganjam, Orissa, India. 
A dose of $5 \mathrm{mgs}$ of maleic hydrazide $(\mathrm{MH})$ per individual was administered with Drosophila food in the treated series and adequate controls were also kept. The testes of the control and treated specimens were fixed separately at 48 hours after the treatment following the procedure described earlier (Manna and Parida 1965). Some specimens died in the treated series due to the effect of the chemical and the rate of survivality in different species was different (Table 1). The percentage of survivality was highest in $O$. velox and lowest in $T$. pulvinata. The frequency was

Table 1. Number of control and treated individuals in different species and their rate of survivality

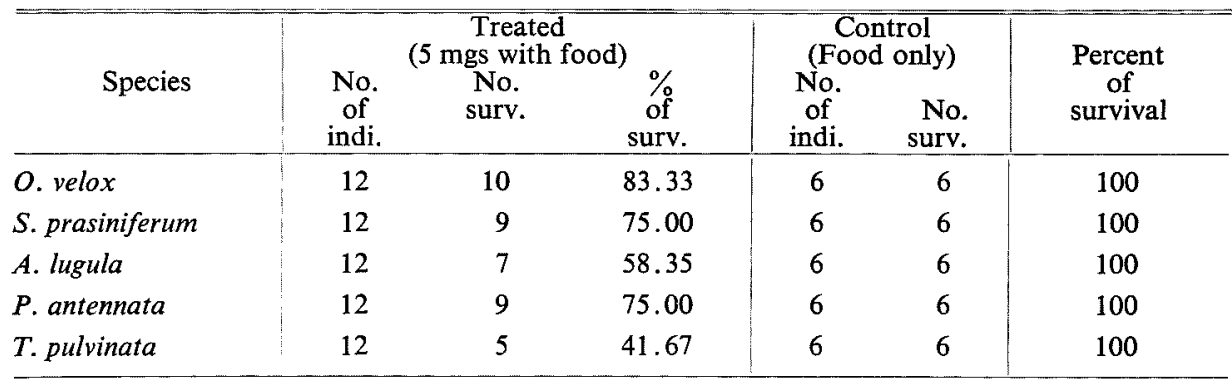

the same in $P$. antennata and in $S$.prasiniferum and it was close to the higher extremity while that of $A$. lugula to the lower extremity. In other words the data would apparently represent that among five species, $O$. velox was most resistant and $T$. pulvinata was most susceptible to the action of MH. However, in the present study more attention has been paid to the chromosome breaking activity rather than the infliction of mortality to the treated individuals.

\section{Results}

A study of 1000 nuclei at diplotene, diakinesis, metaphase I, anaphase I, metaphase II and anaphase II of the control specimens from different species indicated that there was no true break type chromosomal aberration. Occasionally however, some amount of stickiness and gap type aberration in general and very rarely sticky bridge at anaphase I were observed. The total frequency of such type of aberrations in the control series was $1.1 \%$ in $O$. velox, $1.65 \%$ in $S$. prasiniferum, $1.8 \%$ in $A$. lugula, $2.1 \%$ in P. antennata and $1.5 \%$ in T. pulvinata. Thus they would practically lead very little change in the percentage value of aberration obtained in the treated series (Table $2 \mathrm{~A}-\mathrm{E}$ ). Anyhow the net effect of the chemical would be obtained when the control valueis deducted from the treated one. Since the control value was insignificant, we have not put much attention on it.

In the MH treated series various types of chromosomal aberrations were observed and a qualitative account of which will be presented elsewhere (Parida and Manna, unpublished). For the present we have quantitatively analysed the major types of aberrations in five species under consideration (Table $2 \mathrm{~A}, \mathrm{~B}, \mathrm{C}, \mathrm{D}, \mathrm{E}$ ). It is to be mentioned in this connection that there was some overlapping data since 
sometimes a cell had more than one type of aberration. Thus in the total value there was some chance of counting different form of aberrations more than once. As an extreme example, the affected anaphase I might have stickiness, laggards, bridges, and chromosome and chromatid type breaks. In all other stages bridges and laggards would not be encountered. Thus the overlapping effect was recorded more in anaphase $I$ than in any other stage. Since in scoring the data of all the species the same method was applied, the overlapping might have been the same. Therefore, a comparison of the total value, in spite of some limitation, has been made since the chance factor was equal due to randomness. The limitation of overlapping effect was also avoided when the data of a particular type of aberration were compared. Before analysing the individual data and comparing them with each other, it is to be mentioned that the sticky effect which formed the major type of aberration was very palpable in all the species while the break type aberration was relatively rare.

An analysis of the data (Table 2 A-E) would reveal differential chemosensitivity among the different species under present study. The frequency of aberration in any particular stage in different species if compared, some striking difference in the values would be found.

In the diplotene stage the frequency of aberration was highest in $A$. lugula $(31.6 \%$, Table $2 \mathrm{C})$ and lowest in $O$. velox $(4.1 \%$, Table $2 \mathrm{~A})$. The frequency was on the higher side in the remaining three species (Table $2 \mathrm{~B}, \mathrm{D}, \mathrm{E}$ ). In the diakinesis stage the frequency was highest in $T$. pulvinata $(64.7 \%$, Table $2 \mathrm{E})$ and lowest in $O$. velox $(6.8 \%$, Table $2 \mathrm{~A})$. In metaphase $\mathrm{I}$ the frequency was again highest in $T$. pulvinata $(62.0 \%)$ and lowest in $O$. velox $(22.1 \%)$. It is interesting to note that anaphase I, among all other stages, was found to be most sensitive to the action of $\mathrm{MH}$ in all the species under present study (Table $2 \mathrm{~A}-\mathrm{E}$ ). However, the value was found to differ appreciably when the data of different species were compared. It was highest in $P$. antennata $(124.8 \%$, Table $2 \mathrm{D})$ and lowest in $O$. velox $(48.5 \%$, Table 2A). The value in $P$. antennata exceeded even the total number of cells because in good many cases the same cell contained more than one type of aberration. In all the species at metaphase II no other type but the stickiness could only be recorded. The effect was so severe that it prevented the detection of other type of aberration. Anyhow, in metaphase II and in anaphase II the frequency of aberration was highest in $T$. pulvinata $(56.3 \%$ and $54.8 \%$ respectively) and lowest in $O$. velox $(10.8 \%$ and $11.4 \%$ respectively). In the above analysis the striking difference in values was mainly due to the sticky type of aberration. This type was relatively high in the different stages of $T$. pulvinata and $P$. antennata in comparison to that of other species specially $O$. velox. If other types of aberration among the different species were considered, the values would be low but different. Thus when the data of true chromosome and chromatid break type aberration were compared, $T$. pulvinata would show the highest frequency in the stages of diplotene $(3.8 \%)$, diakinesis $(6.08 \%)$, metaphase $\mathrm{I}(9.75 \%)$, anaphase $\mathrm{I}(10.0 \%)$ and anaphase II $(5.7 \%)$ while $O$. velox had the lowest in the corresponding stages e.g., $0.36 \%$ in diplotene, $2.1 \%$ in diakinesis, $3.21 \%$ in metaphase $\mathrm{I}, 8.5 \%$ in anaphase $\mathrm{I}$ and $0.7 \%$ in anaphase II. The values in the remaining species laid between these two extre- 
Table 2. Frequency distribution of different types of aberration induced by $5 \mathrm{mgs}$ MH in five species of grasshoppers

A. O. velox

\begin{tabular}{l|r|r|r|r|r|r|r|r}
\hline $\begin{array}{c}\text { Stage } \\
\text { of } \\
\text { divi. }\end{array}$ & $\begin{array}{c}\text { No. } \\
\text { of } \\
\text { cells }\end{array}$ & $\begin{array}{c}\text { Chro- } \\
\text { matid } \\
\text { break }\end{array}$ & $\begin{array}{c}\text { Chro- } \\
\text { moso. } \\
\text { break }\end{array}$ & Bridge & $\begin{array}{c}\text { Lag- } \\
\text { gards }\end{array}$ & $\begin{array}{c}\text { Sticki- } \\
\text { ness }\end{array}$ & $\begin{array}{c}\text { Total } \\
\text { aberr- } \\
\text { ation }\end{array}$ & $\%$ \\
\hline Diplo. & 550 & - & 2 & - & - & 21 & 23 & 4.1 \\
Diaki. & 380 & 3 & 5 & - & - & 18 & 26 & 6.8 \\
Met. I & 560 & 8 & 10 & - & - & 106 & 124 & 22.1 \\
Anat. I & 210 & 12 & 6 & 20 & 6 & 58 & 102 & 48.5 \\
Met. II & 230 & - & - & - & - & 25 & 25 & 10.8 \\
Ana. II & 280 & 2 & - & 8 & 2 & 20 & 32 & 11.4 \\
\hline Total & 2,210 & 25 & 23 & 28 & 8 & 248 & 332 & \\
$\%$ & & 1.13 & 1.04 & 1.26 & 0.36 & 11.23 & 15.02 & \\
\hline
\end{tabular}

B. S. prasiniferum

\begin{tabular}{l|r|r|r|r|r|r|r|l}
\hline Diplo. & 500 & 2 & 5 & - & - & 108 & 115 & 23.0 \\
Diaki. & 330 & 12 & 6 & - & - & 118 & 136 & 41.2 \\
Met. I & 500 & 8 & 8 & - & - & 235 & 251 & 50.2 \\
Ana. I & 470 & 20 & 5 & 122 & 9 & 91 & 247 & 52.5 \\
Met. II & 400 & - & - & - & - & 126 & 126 & 31.5 \\
Ana. II & 210 & 3 & - & 13 & 5 & 80 & 101 & 48.0 \\
\hline Total & 2,410 & 45 & 24 & 135 & 14 & 758 & 976 & \\
$\%$ & & 1.86 & 0.99 & 5.60 & 0.58 & 31.45 & 40.49 & \\
\hline
\end{tabular}

C. A. lugula

\begin{tabular}{l|r|r|r|r|r|r|r|r}
\hline Diplo. & 300 & 2 & 2 & - & - & 91 & 95 & 31.6 \\
Diaki. & 250 & 10 & 3 & - & - & 82 & 95 & 38.0 \\
Met. I & 500 & 5 & 10 & - & - & 228 & 243 & 48.6 \\
Ana. I & 480 & 22 & 8 & 138 & 11 & 105 & 284 & 59.1 \\
Met. II & 290 & - & - & - & - & 101 & 101 & 34.8 \\
Ana. II & 300 & 4 & - & 10 & 5 & 73 & 92 & 30.6 \\
\hline Total & 2,120 & 43 & 23 & 148 & 16 & 680 & 910 & \\
$\%$ & & 2.02 & 1.08 & 6.98 & 0.75 & 32.07 & 42.92 & \\
\hline
\end{tabular}

D. P. antennata

\begin{tabular}{l|r|r|r|r|r|r|r|r}
\hline Diplo. & 480 & 12 & 6 & - & - & 82 & 100 & 20.8 \\
Diaki. & 360 & 10 & 12 & - & - & 125 & 147 & 40.8 \\
Met. I & 500 & - & 15 & - & - & 202 & 217 & 43.4 \\
Ana. I & 290 & 30 & 2 & 164 & 16 & 150 & 362 & 124.8 \\
Met. II & 300 & - & - & - & - & 108 & 108 & 36.0 \\
Ana. II & 350 & 7 & - & 8 & 2 & 119 & 136 & 38.8 \\
\hline Total & 2,280 & 59 & 35 & 172 & 18 & 786 & 1070 & \\
$\%$ & & 2.58 & 1.53 & 7.54 & 0.78 & 34.47 & 46.92 & \\
\hline
\end{tabular}


E. T.pulvinata

\begin{tabular}{l|r|r|r|r|r|r|r|l}
\hline Diplo. & 500 & 10 & 9 & - & - & 116 & 135 & 27.0 \\
Diaki. & 230 & 9 & 15 & - & - & 125 & 149 & 64.7 \\
Met. I & 400 & 14 & 25 & - & - & 209 & 248 & 62.0 \\
Ana. I & 320 & 27 & 5 & 159 & 10 & 113 & 314 & 98.1 \\
Met. II & 270 & - & - & - & - & 152 & 152 & 56.3 \\
Ana. II & 350 & 10 & 10 & 10 & 3 & 159 & 192 & 54.8 \\
\hline Total & 2,070 & 70 & 64 & 169 & 13 & 874 & 1190 & \\
$\%$ & & 3.38 & 3.09 & 8.16 & 0.62 & 42.22 & 57.48 & \\
\hline
\end{tabular}

mities (Table 2B, C, D). Further, if the frequency of anaphase I and II bridges in different species was compared, the highest value would be found in $P$. antennata $(26.8 \%)$ and the lowest in $O$. velox $(5.7 \%)$. The values in the remaining species were $25.3 \%$ in $T$. pulvinata, $18.9 \%$ in $A$. lugula and $19.8 \%$ in $S$. prasiniferum. In this way several types of differential responses could be brought out among five species of the present study.

Leaving aside the frequency of aberration in different stages as considered above, if we compare the combined data of any particular type of aberration in different species, the differential chemosensitivity would also be apparent (Table 3 ).

Table 3. Percentage values of different types of aberrations in five species compiled from Table 2

\begin{tabular}{l|c|c|c|c|c|c}
\hline \hline \multicolumn{1}{c|}{ Species } & $\begin{array}{c}\text { Chro- } \\
\text { matid } \\
\text { break }\end{array}$ & $\begin{array}{c}\text { Chro- } \\
\text { mosome } \\
\text { break }\end{array}$ & Bridges & Laggards & Stickiness & Total \\
\hline O. velox & 1.13 & 1.04 & 1.26 & 0.36 & 11.22 & 15.02 \\
S. prasiniferum & 1.86 & 0.99 & 5.60 & 0.58 & 31.45 & 40.49 \\
A. lugula & 2.02 & 1.08 & 6.98 & 0.75 & 32.07 & 42.92 \\
$P$. antennata & 2.58 & 1.53 & 7.54 & 0.78 & 34.47 & 46.92 \\
T. pulvinata & 3.38 & 3.09 & 8.16 & 0.62 & 42.22 & 57.48 \\
\hline
\end{tabular}

An analysis of the data (Table 3) would reveal that the frequency of chromatid type break was highest in T. pulvinata $(3.38 \%)$ and lowest in $O$. velox $(1.13 \%)$ while it was $2.58 \%$ in $P$. antennata, $2.02 \%$ in $A$. lugula and $1.86 \%$ in S. prasiniferum. As regards the chromosome type break, the frequency was also highest in T. pulvinata and lowest in $O$. velox. The difference in values was gradual among $S$. prasiniferum, $A$. lugula and $P$. anetennata (Table 3 ). When the frequency of bridges was compared, it was again highest in $T$. pulvinata and lowest in $O$. velox. The difference in frequency was gradual among the remaining species and it was much higher than that of $O$. velox. The frequency of lagging chromosomes was however, highest in A. lugula and lowest in $O$. velox. A comparison of the total aberration frequency (Table 3) showed that it was highest in T. pulvinata and lowest in $O$. velox while remaining ones had values gradually seriated on the higher range. If five species of grasshoppers tested here are to be arranged according to their sen- 
sistivity to $\mathrm{MH}$ action, the serial order would be first $-T$. pulvinata, second $-P$. antennata, third-A. lugula, fourth-S. prasiniferum and fifth-O. velox.

\section{Discussion}

Before we make any conclusive remark on the differential responses of the five species of grasshoppers shown by the aberration frequency of the spermatocyte chromosome to the action of $\mathrm{MH}$, we need to consider some influencing factors. In the study of intraspecific radiosensitivity, factors like temperature (Giavelli and Parazzi 1964), age (Ducoff and Bosma 1966), sex (Glass 1940), stages of division (Whiting 1940), strain (Demerec et al. 1938) etc., were found to have influences on the data. The present interspecific differential chemosensitivity study could not be carried out in an ideal situation. Some of the influencing factors referred to above could not be fully avoided. But these factors very likely did not have much influence because the specimens of different species were collected in the same season and from the same locality. The age of the specimens was, therefore, more or less the same. Moreover, the effect of these influencing factors on the frequency of chromosome aberration in terms of radiosensitivity and chemosensitivity has not been tested in grasshoppers. In the absence of any such critical data on grasshopper material however, the possibility cannot be ruled out. On the other hand, we may well assume that if a study was made in such an ideal condition where influences of these factors could properly be assessed or avoided, the differential values of the aberration frequency obtained for the different species might alter to some extent but it would certainly still indicate the differential chemosensitivity. This is because we have considered values from the present data which were very strikingly different. Therefore, without putting too much importance on the exact difference in quantitative value, we can simply suggest that the different species responded differentially to the action of $\mathrm{MH}$.

In the present data it was found that among the meiotic stages, anaphase I was specially sensitive to the action of MH. Differential sensitivity of meiotic stages to x-rays has also been recorded in Habrobracon (Whiting 1940, 1945a, b). The reason for the particular stage sensitivity in grasshopper could not be understood but the higher frequency was partly due to the scoring of data of some overlapping effects. But if any particular type of aberration was considered where the question of overlapping effect would not arise, the frequencies were still higher than that of any other stage. It may suggested that since in this stage the chromosomes separated, the effects were more visible.

Some amount of mortality of the specimens in five species of grasshoppers in the MH treated series was observed (Table 1). That was most likely due to the toxic effect of the chemical since no mortaility was found in the control series. The effect was however, differential because the death rate was not the same. In the analysis it was revealed that the differential rate of mortality was not related with the size of the body of specimens in different species. According to the body-size $A$. lugula was largest and $S$. prasiniferum was smallest of all but the mortality rate was of reverse nature. It was about $42 \%$ in $A$. lugula and $25 \%$ in $S$. prasiniferum. 
Further, T. pulvinata which showed the highest rate of mortality (about $58 \%$ ) had their body-size in between the above two species. Further, P. antennata had bodysize close to $T$. pulvinata but the mortality rate was only $25 \%$. Thus the difference in the body-size in different species had no relationship with the differential chemosensitivity shown by them.

In the study of interspecific radiosensitivity, the length of chromosomes (Sharma and Chatterjee 1962), position of the centromere (Sparrow 1962), number of chromosomes (Clark and Kelly 1950) and so on have been found to be related with the amount of radiation injury. In this respect the chromosome of short horned grasshoppers appeared to be very ideal for the study of interspecific chemosensitivity because the centromeric position, the diploid number and the length of the chromosomes in species of different genera were not markedly variable as generally found in most other groups of animals. The Cryptosacci group of grasshoppers has been characterised by the presence of 23 acrocentric chromosomes in males (White 1954) and the metrical study conducted in 15 species by Manna (1954) yielded the average length of haploid set of chromosomes between 27.60 and 37.16 microns. In Acrida turrita (Manna 1954) and T. pulvinata (Manna and Mazumder 1967) the value of haploid set of chromosomes was 33.4 microns and in Oxya sp. it was 29.83 microns (Dutt 1955). All the species under present study had more or less the same diploid number, acrocentric form and average length. Only in $T$. pulvinata some variation had in diploid number (Manna and Mazumder 1965, 1967) but other conditions were same as other species. Thus the differential responses of the meiotic chromosomes of five species of grasshoppers were not due to their length, number and centromeric position but most probably due to some intrinsic factors contained in their chromosomal get up.

Manna and Mazumder (1968) in their study on the intra- and interspecific radiosensitivity used the $X$ chromosome aberration as the indicator in eight species of grasshoppers. Five species of the present study were common to their study. The following decreasing order of $\mathrm{x}$-ray sensitivity in these five species was obtained by them (Manna and Mazumder 1968): 1) T. pulvinata, 2) P. antennata, 3) $O$. velox, 4) A. lugula and 5) S. prasiniferum. In the present study of $\mathrm{MH}$ sensitivity, the order obtained was the same as above except for the fact that $O$. velox occupied the fifth position. Thus it is very interesting to note that the order of susceptibility in four among five species (exceptional $O$. velox) remained unaltered with regard to $\mathrm{x}$-ray and MH sensitivity. Since in both types of studies the degree of chromosome aberration was taken as the indicator, it is logical to suspect that some intrinsic factor in the chromosome of these species of grasshoppers was different for which they responded more or less in the similar manner to the physical and chemical mutagens.

Maleic hydrazide is known to be a structural isomer of uracil (Loveless 1953). Very likely it induced chromosome aberrations because of its antimetabolitic action during nucleic acid synthesis. It could also react with $-\mathrm{SH}$ groups in the cell (Muir and Hausch 1953). It was found to inhibit irreversibly certain enzyme requiring free -SH groups (Hughes and Spragg 1958). Kihlman (1966) has made a review on the probable mechanism of action of $\mathrm{MH}$ in the induction of chromosome 
aberration. Probably $\mathrm{MH}$ is incorporated in place of normal base of nucleic acids. It may be bound in some unspecific manner to nuclear proteins and also to nucleic acids. The cytological effects induced by $\mathrm{MH}$ may be due to the alteration in protein component of chromosomes and/or due to its action as antimetabolite into loosely linked DNA-RNA-protein complex. Since the mechanism of action will be dealt with elsewhere by the present authors, for the present in order to explain the differential chemosensitivity observed in the five species, it may be assumed that the distribution of chemical components, both qualitatively and quantitatively, is not the same in all the species. Kihlman (1961) has claimed that the heterochromatic region in the chromosomes of Vicia were more specifically broken due to the treatment of MH. Our result is not in full agreement with that of Kihlman (1961), because the $\mathrm{X}$ chromosome of male grasshopper is known to be heterochromatic and it was not selectively broken. Besides some autosomes were broken in which no localised heterochromatic segment was known. However, the behaviour of heterochromatin is much variable. In this situation the specificity of action of MH on heterochromatin cannot be entirely ruled out and further verification in this line is needed. Pending fruther critical evaluation it may be concluded at present that the chemical get up of the chromosomes in different species of grasshoppers is different for which they responded differentially to the $\mathrm{MH}$ treatment.

\section{Summary}

The relative effect of maleic hydrazide, administered at the rate of $5 \mathrm{mg}$ per individual, on the spermatocyte chromosomes of five species of grasshoppers has been studied. In the control species, the effect was practically nil. In the treated series, it was manifested in the form of chromatid and chromosome type breaks, laggards, bridges etc. The species arranged in decreasing order of effect, are: i) $T$. pulvinata, ii) $P$. antennata, iii) $A$. lugula iv) $S$. prasiniferum and v) $O$. velox. The differential responses have been critically analysed in various ways. Discussions have been made on the role of some influencing factors over the present data. The data have also been compared with the $\mathrm{x}$-ray induced ones.

\section{Literature cited}

Clark, A. M. and Kelly, E. M. 1950. Differential radiosensitivity of haploid and diploid pupae and prepupae of Habrobracon. Cancer Res. 10: 348-352.

Dutt, M. K. 1955. On the chromosome complement and meiosis in nine species of Indian grasshoppers. Proc. Zool. Soc. (Cal.) 8: 111-129.

Demerec, M., Kaufmann, B. P. and Hoover, M. E. 1938. The gene. Carnegie Inst. Wash. Year Book 37: 40-47.

Ducoff, H. S. and Bosma, G. C. 1966 . The influence of pupal age on the sensitivity to radiation. Biol. Bull. 130: 151-156.

Giavelli, S. and Parazzi, E. 1964. Effects of low temperature on radiosensitivity of Drosophila pupae. Intern. J. Rad. Biol. 7: 465-471.

Glass, H. B. 1940. Differential susceptibility of the sexes of Drosophila to effects of $x$-rays in producing chromosome aberrations. Genetics 25: 117. 
Hsu, T. C. and Somers, C. E. 1961. Effect of 5-bromodeoxyuridine on mammalian chromosomes. Proc. Nat. Acad. Sci. (U. S.) 47: 396-403.

Hughes, C. and Spragg, S. P. 1958. The inhibition of mitosis by the reaction of maleic hydrazide with sulphydryl groups. Biochem. J. 70: 205-212.

Kihlman, B. A. 1961. Biochemical aspects of chromosome breakage. Advances in Genetics 10: $1-59$.

- 1966. Actions of Chemicals on Dividing Cells. Prentice Hall Inc. N.J.

Loveless, A. 1953. Chemical and biochemical problems arising from the study of chromosome breakage by alkylating agents and heterocyclic compounds. Heredity (Suppl) 6: 293298.

Manna, G. K. 1954. A study of chromosomes during meiosis in fifteen species of Indian grasshoppers. Proc. Zool. Soc. (Cal.) 7: 39-58.

- 1969. Some aspects of chromosome cytology. Presidential Address, Section of Zoology and Entomology, Proc. 56th Ind. Sci. Congr. 2: 1-30.

- and Lahiri, M. 1966. The effects of cupferron on the spermatocyte chromosome of three species of grasshoppers. J. Cytol. and Genet. 1: 75-85.

- and Mazumder, S. C. 1964. Ethyl alcohol induced sex chromosome breakage in the grasshopper, Phloeoba antennata. Naturwissen. 24: 646.

- and - 1965. 'Supernumerary' or 'Degenerated' chromosomes in a chromosomally aberrant Cryptosacci grasshopper, Tristria pulvinata Uvarov. Experientia 21: 139.

- and - 1967. Evolution of caryotype in an interesting species of grasshopper, Tristria pulvinata. Cytologia 32: 236-247.

- and - 1968. Induced X chromosome aberrations in the study of intra- and interspecific radiosensitivity of grasshoppers. Proc. Intern. Seminar on Chromosome. Nucleus Supplement. Vol. 197-207.

- and Parida, B. B. 1965. Differently administered colchicine effects upon the testes cells of the grasshopper, Spathosternum prasiniferm. Cytologia 30: 392-401.

Muir, R. M. and Hauch, C. 1953. On the mechanism of action of growth regulators. Plant Physiol. 28: 218-232.

Sax, K. and Swanson, C. P. 1941. Differential sensitivity of cells to x-rays. Amer. J. Bot. 28: 52-59.

Sharma, A. K. and Chatterjee, A. 1962. Chromosome size as a factor in radiosensitivity. Nucleus 5: $67-74$.

Spalding, J. F. and Brooks, M. C. 1962. Comparative radiosensitivity of three lines of mice with different ancestral histories of exposure to ionizing radiations III. Resistance to single acute x-ray exposure. U. S. Atomic Energy comm. Res. and Dev. Rep., Lams 2980: 125-127.

Sparrow, A. H. 1962. The role of nucleus in determining radiosensitivity. Brookhaven Lecture Series No. 17.

White, M. J. D. 1954. Animal Cytology and Evolution. Second Edition. Univ. Press, Cambridge.

Whiting, A. R. 1940. Sensitivity of x-rays on different meiotic stages in unlaid eggs of Habrobracon. J. Exp. Zool. 83: 249-269.

- 1945a. Effects of x-rays on hatchability and on chromosomes of Habrobracon eggs in the first meiotic prophase and metaphase. Amer. Natur. 79: 193-227.

- 1945b. Dominant lethality and correlated chromosome effects in Habrobracon eggs x-rayed in diplotene and late metaphase. Biol. Bull. 89: 61-71. 